\title{
Las organizaciones campesinas bolivianas: entre la oficialidad y la autonomía (1964-1982)
}

Guadalupe Rodríguez de Ita INSTITUTO MORA

Presentación

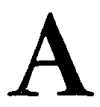
todo lo largo del proceso histórico de América Latina, los campesinos han ocupado un sitio de gran importancia tanto cuantitativa como cualitativamente. En Bolivia, pese a la gran significación económica que ha tenido tradicionalmente la minería, la mayoría de la población se ha dedicado también a la agricultura. En las últimas décadas cerca de las dos terceras partes de los habitantes viven y trabajan en el campo. Por otra parte, esta población se ha distinguido, desde tiempos ancestrales, por su combativa participación en el desarrollo histórico del país.

No obstante su trascendencia, el campesinado boliviano y su organización y vinculación con otros sectores, ha sido poco estudiado, en comparación, por ejemplo, con la clase obrera $y$, en particular, con los mineros a cuyo análisis se han dedicado ya varios trabajos. Por tanto, parece conveniente ocuparse del estudio de este sector, así en forma general como en casos específicos. En esta última vertiente se inscribe el presente trabajo que estudia la conexión establecida por lo que se conoce como Pacto Militar-Campesino, entre los trabajadores del campo y los miembros de las Fuerzas Armadas en el periodo 1964-82, esto es, desde la ocupación del gobierno por los militares hasta el retorno a la civilidad. Lo que se pretende mostrar aquí es que, dada la heterogeneidad de los sectores involucrados en el Pacto, esa vinculación no es lineal ni uniforme, y en ella las 
organizaciones campesinas oscilan entre la oficialidad y la autonomía.

\section{HaCia La SUBORDINACIón}

La historia reciente de Bolivia tuvo un importante parteaguas con el triunfo de la llamada Revolución Nacional ${ }^{1}$ de abril de 1952. En ese año, diversos sec. tores sociales del pueblo en general, hicieron efectivo por la vía armada el triunfo electoral obtenido el año anterior por Víctor Paz Estenssoro, líder del Movimiento Nacionalista Revolucionario (MNR), que se instalaría así en el poder con un programa de unidad nacional; éste se componía de un proyecto desarrollista con un modelo de acumulación basado en la ampliación del mercado interno, en la sustitución de importaciones alimentarias y en la creación -bajo la protección estatalde una burguesía nacional progresista que invirtiera en la industrialización.

Consecuente con sus ideas antiimperialistas, antioligárquicas y populares y ante la iniciativa de las masas, el MNR nacionalizó la minería y se planteó la necesidad de realizar cambios en materia agraria. Además, con el fin de incorporar a toda la población a la democracia formal, se dictaron cambios en la ley electoral, siendo el más importante la instauración del sufragio

1 "Por revolución nacional se entiende en Bolivia el periodo de las transformaciones democráticas que comenzaron en abril de 1952. Es un apelativo que se le atribuye a Carlos Montenegro, el teórico fundamental del nacionalismo revolucionario..." Zavaleta, Lo nactonal, 1984, p. 10. Sobre este hito de la historia boliviana puede consultarse A ntezana, Historia, 1988. universal. Con el objeto de ensanchar su base social, los movimientistas in. trodujeron medidas distributivas que no alteraran las relaciones de producción; se proponían convertir a los campesinos en productores y consumidores y, en general, trataron de integrar a los indios-campesinos a la vida nacional, así fomentaron la sindicalización masiva, la formación de milicias obreras y campesinas, y el funcionamiento de los llamados comandos del partido.

Ante la necesidad de extenderse y consolidarse, el MNR en el poder y otros partidos e incluso la Central Obrera Boliviana (COB), ${ }^{2}$ enviaron delegados al campo y lograron influir en algunos dirigentes regionales. Al mismo tiempo, los campesinos se reorganizaron por su cuenta. En Cochabamba -donde ya existían antecedentes organizativos-, los trabajos de sindicalización avanzaron con rapidez, pero con algunos problemas ya que surgieron -o mejor dicho resurgieron- viejas rencillas que se manifestarían en la división entre radicales del valle bajo y moderados del valle alto. ${ }^{3}$

Por su rápida organización la región de los valles cochabambinos se convirtió en prioritaria para el régimen; en

2 Lazarte, Movimiento, 1989, pp. 183 a 201. En él se anexa el documento de fundación de la COB, pp. 279 a 281.

3 "Este primer ejemplo de rivalidad entre líderes y división dentro del mismo sindicato habría de tornarse en una característica frecuente del movimiento campesino en expansión. [...] Una vez cubierto el escenario local, la rivalidad entre líderes habría de transformarse en una competencia por el control de organizaciones en el nivel provincial y finalmente de la misma Federación Departamental [...]" Dandler, "Campesinos", 1986, pp. 229 y 230. 


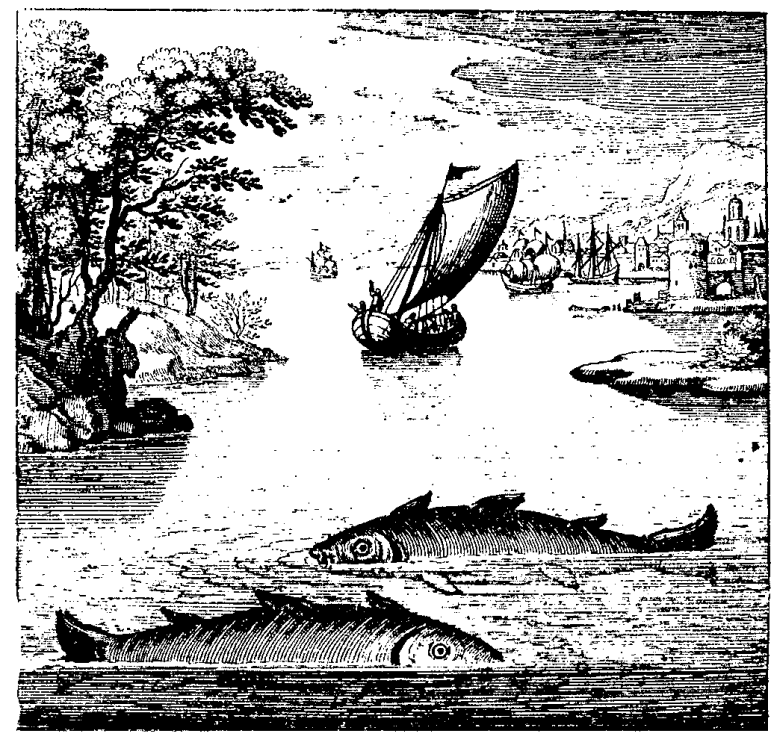

ella se formó "una de las redes más tempranas de intermediarios políticos para el gobierno". ${ }^{4}$ A partir de aquí la formación de sindicatos y milicias se extendería en haciendas y comunidades, desde los valles hasta el altiplano. La sindicalización en las tierras bajas orientales fue más lenta debido a que, en ese periodo, apenas empezaban a ser colonizadas para su explotación.

En el decreto de Reforma Agraria, 5 el sindicalismo campesino fue reconocido oficialmente como instrumento

4 Rivera, “Apuntes", 1985 , p. 182.

5 Vid. Decreto Supremo No. 3464 de Reforma Agraria en Del Castillo. Compilación, 1955 , y en Menjivar, "La Reforma", 1969, pp. 287 a 329. Sobre este tema existe una extensa bibliografia, destacándose los trahajos de Canelas, $M i$ to, 1966, y de Urquidi, Bolitia, 1969, y El feudalismo, 1966. de defensa de los derechos campesinos y donde éstos no existían fueron creados desde arriba. Así se fundaría, el 15 de julio de 1953, la Confederación Nacional de Trabajadores Campe. sinos de Bolivia (CNTCB), ${ }^{6}$ que en breve se afiliaría a la $C O B$; dirigentes superiores colaboraron en la formación de las federaciones departamentales, desde las cuales, se crearon las centrales y subcentrales provinciales y cantonales que contribuyeron, a la vez, a la organización sindical local.

El reconocimiento oficial del sindicalismo y el apoyo del partido en el gobierno actuaron positivamente sobre la organización sindical al facilitar

6 Cárdenas, "Notas", 1985, p. 94; Lazarte, Mfovimiento, 1989, p. 188; Huizer, El potencial, 1973 , pp. 177 y 178. 
su rápido crecimiento pero, a la vez, le generarían varios defectos de raíz que resultarían difíciles de superar, como la dependencia estructural (vertical y burocrática) y económica respecto al gobierno. $^{7}$

Promulgando el decreto de Reforma Agraria y repartiendo armas entre los indios, así como a través de diferentes prebendas otorgadas a los dirigentes (cargos de diputados y senadores, sueldos especiales, posibilidades de poder ejecutivo, administrativo y judicial en su sitio de control y cupos alimenticios en las comunidades altiplánicas) y alentando las contradicciones y rivalidades entre los líderes, el MNR cooptaría poco a poco a las zonas campesinas más peligrosas e incidiría en la estructura sindical, pero no lograría la completa hegemonía sobre este sector.

Entre otras razones, el temor a ser de nueva cuenta despojados de sus tierras, así como a seguir siendo oprimidos económica, social e incluso culturalmente por comerciantes, intermediarios, autoridades y agentes urbanos llevaría al campesinado a organizarse en sindicatos. De allí que

Por la voluntad propia de los campesinos, el sindicalismo se convierte para ellos en un instrumento de lucha y liberación, con caracteres propios y como expresión de su poder local y regional. Hacen de él una especie de poder local con

7 "El sindicalismo campesino es un 'sindicalismo invertido' donde los dirigentes superiores no están en función de las bases sino en función de sus propias conveniencias y prestigio personal. I. a corriente de las consignas va desde arriba para abajo pero no de abajo para arriba" Iriarte, Sindicalismo, 1980, p. 88. base autónoma y un vínculo con la sociedad nacional y con el partido. ${ }^{8}$

Es de anotar que, a nivel local, en los valles y zonas de colonización se presentaría con más frecuencia la corrupción y la tendencia al caciquismo de los líderes, donde los cargos sindicales serían aprovechados para obtener ventajas materiales; en el altiplano, los dirigentes defenderian en general los intereses de las bases. ${ }^{9}$ Además el liderazgo sindical contribuiría a la reestructuración de los circuitos mercantiles, controlados hasta entonces por los terratenientes.

\section{CONTROL MILITAR A TRAVES DEL PACTO}

Durante los gobiernos movimientistas -esto es entre 1956 y 64-, los campesinos, manipulados paternalistamente sobre la base de su incorporación política vía el sufragio universal y habiendo logrado sus objetivos inmediatos al completarse la primera fase de la Reforma Agraria, se mantuvieron hasta cierto punto unidos al partido en el poder.

El fracaso de la política del MNR para contribuir a la formación de una burguesía nacional fuerte, los agudos desa. justes económicos provocados por la problemática nacionalización de las minas, las medidas incompletas aplicadas en el campo y la injerencia norteamericana cada vez mayor en distintos órde. nes, entre otras causas, favorecieron las pugnas intrapartidistas, la paulatina

$8 \mathrm{Ibid}$., p. 38.

9 Ibid., pp. 80 y 81 . 
pérdida de sus bases sociales de apoyo y la intromisión sistemática de las Fuerzas Armadas en la vida social y política boliviana. En este marco, los lazos que vinculaban a los trabajadores del campo entre sí y con otros sectores se diluyeron para dar paso a la fragmentación; se rompió la alianza obrero-campesina y se inició el acercamiento de estos últimos con los militares.

Hacia 1963, la división campesina llegó a un punto álgido, cuando los miembros considerados de izquierda por los líderes oficialistas fueron expulsados del Congreso Nacional Campesino, expulsión que se llevó a cabo como respuesta a la celebración de una conferencia departamental en la que se criticó la aplicación de la Reforma Agraria. Los campesinos expulsados organizaron su propio Congreso Nacional, en Cochabamba. ${ }^{10}$

Con este contexto se abriría una buena posibilidad para que el ejército, argumentando la necesidad de frenar los choques que se producían en el campo, tuviera una mayor participación e influencia en algunas regiones; esta influencia se reforzaría con el desarrollo del llamado Plan de Acción Cívica $^{11}$-enmarcado en la política exterior norteamericana de respuesta flexible ${ }^{12}-$, que les permitiría movili-

${ }^{10}$ Dandler, "La Ch'ampa", 1986, p. 270.

11 "Acción Cívica es un programa de obras de desarrollo social a cargo del Fjército de Bolivia, en conperación con las FF.A A. de Estados Unidos en el que participan también las comunidades a través de juntas vecinales, sindicatos, cooperativas y organizaciones cúlturales. Está financiado por la A lianza para el Progreso." Llosa, René. 1966, pp. 236.

12 En lo que se refiere a la política exterior norteamericana de este periodo puede consul- zar recursos materiales y técnicos de los que obtendrían resultados políticos fecundos "ya que producen la adhesión campesina hacia el ejército y la constitución del monopolio político del aparato militar del área rural". ${ }^{13} \mathrm{Al}$ mismo tiempo, las altas jerarquías de las Fuerzas Armadas tomaron iniciativas que les permitieron formalizar $y$ fortalecer su participación política; así, la Célula Militar del MNR dio a conocer sus bases programáticas ${ }^{14}$ en las que definió su línea política de asumir los principios del MNR manifestando su interés por "estrechar vínculos partidarios con los campesinos".

Entre los elementos del ejército que intervinieron en estas actividades destaca la figura del general René Barrientos Ortuño, quien consiguió imponer un acuerdo de paz entre los campesi. nos de Cliza y Ucureña que se encontraban en pugna, neutralizando allí tanto a izquierdistas como a centristas y suscribiendo un Pacto Anticomunis. ta Militar-Campesino. ${ }^{15}$

En las elecciones de 1964, en las que el MNR volvió a proponer a Paz Estenssoro para la presidencia, entre la alta oficialidad del ejército se perfiló el general Barrientos como el candidato

tarse Fernández, El gran, 1986, pp. 27 a 34; Insulza, "La primera", 1984, pp. 296 a 354.

${ }^{13}$ Jiménez, El Estado, 1980, p. 106.

14 Vid. "Bases programáticas" en Prado, Po. der, 1984, p. 131.

is No obstante la importancia del pacto entre campesinos y militares, los estudios realizados no mencionan o no concuerdan en el año de su establecimiento. Ardaya, "Ejército", 1985, p. 43, afirma que el pacto se firmó en el año 1963. Prado, Poder, 1984, p. 141, anota que fue en el año 1964. Dandler, "La Ch'ampa”, 1986, p. 273 , no puntualiza la fecha. 
idóneo para la vicepresidencia, que contaba además con la simpatía del gobierno de Estados Unidos debido a su colaboración en la aplicación del men. cionado Plan de Acción Cívica. Realizados los comicios, se consumó la reelección de Paz, pero su situación se tornó insostenible por intentar poner en práctica una política económica burocrática y desarrollista.

En este marco, la burguesía reaccionaria, un sector militar del propio MNR encabezado por el general Barrientos y representantes del capital estadunidense, se organizaron para entrar en escena en el momento más propicio a fin de contener el movimiento social en ascenso. ${ }^{16} \mathrm{El}$ golpe fue preparado meticulosamente y ejecutado con precisión y oportunidad: el 4 de noviem. bre de 1964, el presidente Víctor Paz fue obligado a dimitir; el alto mando de la institución militar proclamó el triunfo de lo que denominaban Revolución Restauradora o Revolución Bo. liviana ${ }^{17}$ y resolvió formar una Junta Militar de Gobierno integrada por el general de división Alfredo Ovando y el general de la Fuerza Aérea René Barrientos, proclamando a las Fuerzas Armadas como institución tutelar sin pertenencia a ningún partido y disolviendo la Célula Militar del MNR. ${ }^{18}$

Una vez en el poder, Barrientos, aliado a importantes sectores de derecha

16 Miranda, "Bolivia", 1973. pp. 28-35; Prado, Poder, 1984, pp. 145-152.

${ }^{17}$ En la retórica oficialista se sustituye entonces el término de Revolución Nacional por el de Revolución Boliviana. Miranda, "El populismo", 1983, p. 127.

18 Véase el decreto correspondiente en Prado, Poder, 1984, p. 162. y en nombre de esta Revolución Boliviana encaminó su política económica a favorecer a las clases dominantes y a las compañías transnacionales. ${ }^{19}$ Por su parte, siguiendo la línea del nacionalismo revolucionario, Ovando propugnó por el control de la metalurgia y la siderurgia como base de la independencia del país. Con el fin de garantizar el ritmo de acumulación, la Junta elaboró un Plan de Reorganización Económica que contemplaba: decrementos salariales generalizados (hasta del $40 \%$ en las minas), despido de trabajadores, intervención de sindicatos y desarme de milicias obrero-campesinas.

Por lo anterior el régimen enfrentaba gran agitación social urbana entre los obreros y las clases medias por las difíciles condiciones de vida. Por su lado, gran parte del campesinado -sobre todo el cochabambino, contando con la promesa de que sus tierras no le serían arrebatadas- se convirtió en la principal base de masas del gobierno, liderado por personas adeptas a él, produciéndose así un alejamiento entre obreros y campesinos.

Los militares en el poder trataban de extender a todo el país el sometimiento coactivo del campesinado teniendo como principal mecanismo el establecimiento de pactos promovidos en forma personal por Barrientos

19 De esta manera, la crisis de la burocracia política y de las clases dominantes permite la sustitución de la hegemonía civil por la militar con lo que se modifica el bloque de poder, que. dando en éste nuevas fracciones de la burguesía interna (minero-exportadora, agro-industrial y financiera) y extranjera (norteamericana), donde la última se constituye en fracción dominante. Jiménez, El Estado, 1980, pp. 112 y 113. 
que recorría el territorio ganándose el apoyo tanto de las bases - por medio de regalos en dinero o en especie-, como de dirigentes medios -ofreciéndoles posibilidades de ascenso a diputaciones y otros cargos.

En esta forma,

el régimen de Barrientos se fundó en lo que se bautizó como "pacto militarcampesino", es decir, entre el sector menos politizado del movimiento democrático y el sector de la burocracia estatal más penetrado por el imperialismo. 20

Se sustituyó así la articulación sindicato-partido, vigente durante los gobiernos movimientistas, por la relación sindicato campesino-ejército. ${ }^{21}$

En este periodo, se multiplicaron las federaciones especiales, las centrales y las subcentrales con lo que,

las organizaciones departamentales o regionales fueron perdiendo fuerza $y$, en cambio, cada sindicato y cada dirigente pasaba a depender directamente del "líder máximo", es decir, de un militar que ni siquiera era campesino y que tenía otros intereses. ${ }^{22}$

Para debilitar a los sectores opositores, se siguió con la práctica pazestenssorista de crear sindicatos paralelos manejados desde arriba y se promovió la creación de cooperativas dirigidas por el gobierno. Al mismo tiempo se dio mayor impulso a las actividades de Acción Cívica y al Desarrollo de las Comunidades. "Con ello quería demos-

20 Zavaleta, "Consideraciones", 1982, p. 119.

21 Ardaya, "Democracia", 1985, p. 37.

22 Iriarte, Sindicalismo, 1980, p. 56. trar que era más fácil lograr cosas (escuelas, caminos, etc.) alabando al gobierno que a través de la organización y la lucha de las bases". ${ }^{23}$

Con base en la información encontrada, durante la gestión militar de 1964 a 1969, la represión a campesinos fue nula, más aún se les otorgaron algunas "concesiones", por ejemplo: luego de algunas protestas, se les permitió conservar las armas que tenían en su poder desde el triunfo movimientista. En un primer momento se les apoyó frente a los ex gamonales que, ante el caos reinante, pretendían eliminar a las autoridades campesinas para instalarse ellos en sus puestos.

Con estas actividades se obtuvo cierto éxito sobre todo en los valles de Cochabamba y Potosí cuyas organiza. ciones locales se aseguraron beneficios asistenciales de la administración militar, a cambio de respaldo político; con esto el campesinado logró un margen de negociación a cambio de legitimar al régimen.

Fortalecidos en el gobierno, en 1965, los militares disolvieron los comités directivos y nombraron dirigentes adeptos. Así, los mecanismos de mediación establecidos durante los regímenes movimientistas se tornaron mecanismos de control y se fortalecieron los lazos verticales y personales entre Barrientos y los campesinos. El sindicalismo de base adoptó la forma de un sistema patronal, entonces con un patrón más paternalista.

Gran parte del campesinado, sin condiciones objetivas para elaborar una contraideología, se plegó a un Es.

${ }^{23}$ Ibid. 
tado ya despojado de toda retórica obrerista y se alineó al bloque hegemónico de la clase dominante integrado por la burguesía dependiente, el imperialismo norteamericano y las Fuerzas Armadas.

Las bases y el programa de trabajo, apenas esbozados en el primer pacto, fueron ratificados en documentos posteriores. Las bases político-ideológicas que se plantearon en él fueron:

Prestarse ayuda y cooperación mutua, en aras de los grandes intereses de la patria y en defensa de la soberanía e integridad nacional. l.uchar conjuntamente con los trabajadores del agro por la aplicación de la reforma agraria integral, tecnificación, mecanización y cooperativismo de rurales y obtener la consiguiente mejora del nivel económico y social del campesino. Transformación de las instituciones estatales y creación de nuevos organismos que cancelen estas dos fuerzas, mediante un reordenamiento juridico integral en pro de los grandes objetivos del campesinado. Buscar la promoción de la economía del Estado y la capacidad del crédito público y privado para la ejecución de los planes de desarrollo campesino. 24

De parte del campesinado se estableció que:

Se compromete a movilizar integramente sus bases para contribuir económicamente, a fin de luchar para conseguir en el plano de una generación, su redención espiritual y material y la ansiada

${ }^{24}$ Véase Fundamentos del Pacto militar-campesino, IV Congreso Nacional de Trabajadores Campesinos de Bolivia, Sacasa-Potosí, 9 de enero de 1972 , pp. 7 y 8 ; citado por Jiménez, El Estado, 1980, p. 123. justicia social que se le había negado sistemáticamente para poder intervenir, en igualdad de condiciones, con los demás estamentos sociales y constituir una República integrada por mayorías nacionales al servicio de la patria. 25

Por otro lado se sabe que el progra. ma de trabajo contempla:

Lograr el reajuste de los mecanismos de Reforma Agraria para la equitativa y perentoria titulación que dé por concluida la fase jurídica de la reforma agraria; instaurar el cooperativismo agrario para superar los efectos derivados del minifundio; dotar de un sentido de empresa a la producción delárea rural para evitar la duplicidad de servicios y la dispersión de los recursos humanos, materiales, financieros y, finalmente, garantizar la vigencia de las organizaciones campesinas. 26

\section{EN BUSCA DE AUTODETERMINACIÓN}

A fines de 1965, cumpliendo el ofrecimiento hecho al ascender al poder y buscando legitimarse, la Junta Militar convocó a elecciones generales. El 1 de enero del año siguiente, el general Barrientos renunció a su cargo en el gobierno para participar y, finalmente, triunfar en los comicios, contando con el apoyo de las Fuerzas Armadas y de la CNTCB entre las que se mantenía vigen. te el pacto que había dado sustento al régimen militar desde 1964.

25 Ibid., p. 124.

26 Véase Documento de ratificación y actualización del Pacto militar-campesino para 19761980, Tarija, 24 de octubre de 1976; citado en ibid., p. 124 
Adecuando a un nuevo esquema de dominación los mecanismos sociopolíticos empleados por los movimientis. tas (asistencia estatal paternalista, clientelismo político y manipulación burocrática ligada a la imagen del gobernante), Barrientos logró cierto grado de legitimidad y consenso, así como una declinación del proceso de participación social. Sin embargo, tuvo que enfrentar una serie de problemas poli. tico-sociales de envergadura, como fueron: la división en el interior de las Fuerzas Armadas, un importante movimiento guerrillero y el primer resquebrajamiento en la relación militarcampesina.

En 1966 dirigentes del ejército y de la relativamente unificada CNTCB suscribieron un Pacto en el que los campesinos se comprometieron a apoyar al gobierno de las Fuerzas Armadas, en tanto éste ofreció respetar las conquistas agrarias logradas en los cincuenta. Un año más tarde este acuerdo fue ratificado en el Congreso Nacional de Tarabuco y en 1968 fue discutido $y$ criticado por algunas fracciones campesinas sobre todo cuando el gobierno instrumentó el cobro de un impuesto único sobre la propiedad de la tierra. ${ }^{27}$

Respecto a esta cuestión, cabe señalar que desde los primeros años de la gestión militar y argumentando el bajo monto de los impuestos sobre la tierra en sus dos modalidades -contribución territorial e impuesto catastral-, el gobierno preparó un proyecto que regulara la situación. Surgió la propuesta de cobrar un impuesto único sobre la 288 .

${ }^{27}$ Lavaud, "Los campesinos", 1986, pp. 284 - propiedad de la tierra "calculado sobre la sola base de los bienes raíces, y cuya percepción sería racionalizada". 28

Una vez terminado el proyecto se organizó una intensa campaña propagandística tendiente a obtener el consenso general. Además se realizaron, auspiciados por el gobierno, congresos provinciales y departamentales para elegir delegados a una reunión nacional en la que debía aprobarse la aplicación del impuesto único. En esa época, los dirigentes nacionales y departamentales se hallaban supeditados a Barrientos, y las actividades sindicales campesinas, rígidamente burocratizadas, por lo que resulta hasta cierto punto sencillo incidir en la elección de representantes adeptos al régimen y desligados de los sindicatos de base. No obstante el control gubernamental sobre la población rural, en algunas regiones tuvieron lugar importantes manifestaciones de oposición e incluso se llegó a la virtual ruptura entre una fracción campesina y el gobierno militar. 29

En este contex to se llevó a cabo, el 5 de diciembre de 1968, en La Paz, la Primera Conferencia Económica de Trabajadores Campesinos de Bolivia para abordar los siguientes temas:

${ }^{28}$ Con el impuesto único el Estado no sôlo aspiraba a fortalecerse y centralizarse, sino que además se proponía penetrar e intervenir en forma más directa en el campo y regular los ingresos de las administraciones locales; del mismo modo, al parecer, pretendía utilizar parte de las recaudaciones para indemnizar a los propietarios de las tierras expropiadas por la Reforma Agraria. Ibid.

29 Albó, La cara, 1985, p. 279; Cárdenas, "Notas", 1985, p. 95; Rivera, "Apuntes", 1985, p. 196. 
Asuntos sociales: desarrollo de las comunidades, centralización de los organismos de promoción social.

Asuntos económicos: impuesto único, préstamos supervisados, asistencia técnica, extensión de los mercados. 30

Los campesinos, agrupados por departamentos, discutieron la forma en que se impondría el gravamen en las diferentes zonas y sobre los diversos tipos de propiedad; los de Cochabamba se pronunciaron en favor del impuesto, en tanto que los de La Paz se mantuvieron firmemente en contra. A final de cuentas, la reunión quedó fuera del control gubernamental y varios delegados se retiraron; no obstante, según los voceros oficiales, en la reunión fue consagrada la adopción del impuesto único a nivel nacional. ${ }^{31}$

Los delegados que se retiraron de la Conferencia formaron el Bloque Campesino Independiente (BCI) de Bolivia, constituyéndose en la primera voz opositora en plena vigencia del Pacto Militar Campesino. Fueron apoyados por los universitarios y después por los obreros fabriles de La Paz con quienes firmaron, el 27 de diciembre de ese año, un pacto de alianza. Ante la nueva correlación de fuerzas, tres dias más tarde, el presidente anunció que la aplicación del impuesto se difería hasta nuevo aviso.

Desde su formación, el BCI mostró los primeros indicios de una recomposición de las alianzas campesinas, se mantuvo en buena medida margi-

${ }^{30}$ Lavaud, "Los campesinos", 1986, p. 286.

31 Ibid., pp. 287 a 291. nado del sindicalismo oficial, se afilió a la COB y se opuso abiertamente al Pacto con los militares. ${ }^{32}$ El BCI se desarrolló sobre todo en La Paz y en algunos sectores mineros que, poco a poco, se organizaron contra el Estado y contra Barrientos a quienes identificaban como sus enemigos. Sus promotores más sobresalientes fueron lideres marginados, no necesariamente campesinos, que militaban en partidos de izquierda, quienes, cabe apuntarlo, no lograron articularse por completo con las bases, siendo éste uno de sus principales problemas. 33

\section{LAS CORRIENTES OFICIALISTA \\ Y AUTONOMISTA}

A la muerte de Barrientos, otros militares ocuparon el poder, accediendo por la vía golpista: Alfredo Ovando (196970), Juan José Torres (1970-71) y Hugo Bánzer (1971-78). Con cada uno de ellos, los campesinos establecieron relaciones distintas y en el interior del movimiento se mantuvieron básicamente las dos líneas abiertas durante la gestión barrientista, es decir, la oficialista y la autonomista.

La relativa apertura democrática generada por el gobierno de Ovando y continuada por Torres hizo posible la reorganización campesina, el desarrollo de un nuevo sindicalismo agrario y el surgimiento de nuevas agrupaciones con variadas posiciones respecto al gobierno y al Pacto Militar Campesino. Además tuvieron lugar una serie de

\footnotetext{
32 Rivera, "Luchas", 1983, p. 137.

33 Albó, La cara, 1985, p. 280.
} 
movilizaciones, en particular en las zonas de colonización de oriente. ${ }^{34}$

Entre las organizaciones que aparecieron entonces estaba la Unión de Campesinos Pobres (UCAPO) ${ }^{35}$ que surgió al norte de Santa Cruz y reclamaba los derechos de propiedad sobre latifundios no tocados por la reforma agraria movimientista. Del semiproletariado agrícola surgió, además de la UCAPO, una organizaciôn de carácter claramente sindical, poco ligada a la estructura oficialista: la Confederación de Colonizadores, ${ }^{36} \mathrm{en}$ febrero de 1971, afiliada a la COB.

En la capital, de manera paralela a la acción sindical desarrollada en el altiplano, pobladores de origen aimara crearon el Centro de Promoción y Coordinación Campesina MINK'A con el fin de realizar labores educativas y culturales en el campo y la ciudad; asimismo, el 12 de agosto de 1971 establecieron el Centro Campesino Tupac Katari. ${ }^{37}$

La tradicionalmente oficialista CNTCB, alentada por Torres -en un intento de lograr cierta base social y política en el campo-, celebró el 2 de agosto de 1971 , en Potosí, su VI Congreso Nacional al que asistieron 600 delegados provenientes de las nueve federaciones departamentales y de algunas federaciones especiales. ${ }^{38}$

El aflojamiento de las presiones del Pacto Militar-Campesino sobre la orga-

34 Ibid., pp. 282 a 289; Flores, "Estado", 1986, pp. 456-464.

35 Flores, "Estado", 1986, pp. 456.462.

${ }^{36}$ Iriarte, Sindicalismo, 1980, p. 58; Rivera, "Apuntes", 1985, p. 197.

37 Rivera, "Luchas", 1983, p. 140.

38 Flores, "Estado", 1986, pp. 459-462 nización sindical, hizo posible la recomposición de las directivas en algunas centrales provinciales y federaciones departamentales, principalmente del altiplano, así como en la propia CNTCB. De esta manera, los antiguos caciques barrientistas fueron despla. zados por una nueva generación de dirigentes que ascendieron desde las bases. Esta recomposición tuvo especial significación en el Congreso donde resultó electo, como Secretario General de la CNTCB, el dirigente aimara Jenaro Flores, quien

intentó acercarse a la $C O B$ y a la Asam. blea Popular, pero la izquierda se mostró recelosa de cualquier a proximación al "oficialismo" campesino y mantuvo al Bloque Independiente como única representación campesina en ambos organismos. 39

La realización del Congreso fue repudiada y, en la medida de lo posible, obstaculizada por las organizaciones abiertamente contrarias al gobierno del general Torres y/o al Pacto MilitarCampesino como BIC y UCAPO. ${ }^{40}$

En forma paralela, la actividad del BCI se extendió desde La Paz hacia otros puntos del país, con a poyo cobista. Durante el periodo de la Asamblea Popular, abierto por Torres, en tanto la masa campesina se encontraba marginada del proceso, el BCI-pese a ser un grupo relativamente minoritario-, asumió, como se anotó arriba, la representación campesina en el organismo popular ${ }^{41}$ donde reclamó, argumen-

${ }^{39}$ Rivera, "Luchas", 1983, p. 138.

40 Flores, "Estado", 1986, pp. 456-462.

41 Rivera, "Apuntes", 1985, p. 197. 
tando ser la fuerza social más grande, un mayor número de delegados y logró colocar en la segunda presidencia a un líder campesino.

En 1971, al ascender el coronel Bánzer al poder se terminó con el relativo impasse en que se hallaban las relaciones entre trabajadores del campo e institución castrense. Debido a la escasa base social con la que contaba el régimen del Frente Popular Nacionalista, el gobierno intentó reforzar el Pacto Militar-Campesino y las presiones manipuladoras sobre el sindicalismo agrario extendiendo la persecución y la represión sobre las organizaciones y los líderes campesinos opositores. Pese al clima represivo, una corriente contestataria se desarrolló a lo largo del periodo banze. rista en las diferentes regiones.
El gobierno de Banzer intervino de manera directa o indirecta en la reorganización de las centrales provinciales, federaciones departamentales y en la CNTCB, nombrando a líderes adictos y serviles al régimen para ocupar los más altos cargos. Impulsó la celebración de encuentros y ampliados cam. pesinos; aumentó el número de subcentrales honorificas, prácticamente alejadas de sus bases, y procuró aislar a los campesinos de los grupos políticos que pudieran menguar el monopolio del pacto. ${ }^{42}$ Desconoció el VI Congreso efectuado en Potosí, en agosto de 1971 y persiguió y encarceló a sus dirigentes; con el objeto de realizar un

42 Iriarte, Sindicalismo, 1980, pp. 59 y 60; Urioste, El Estado, 1984, p. 147.

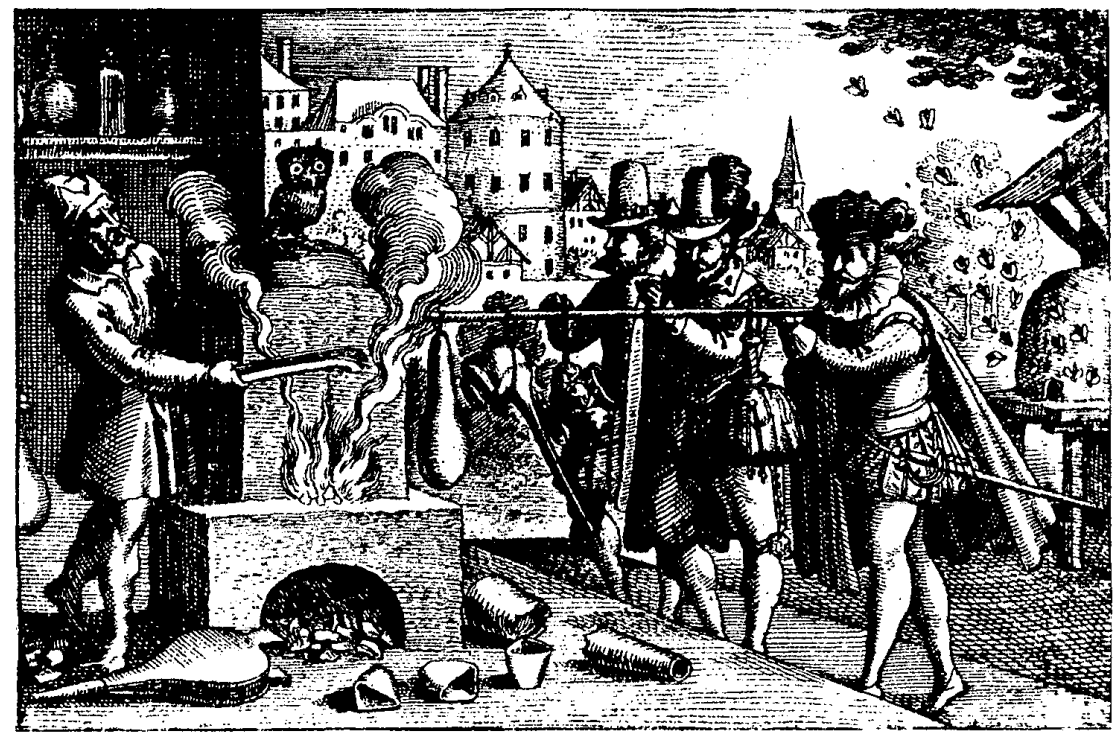


nuevo congreso nacional, promovió numerosas concentraciones y reuniones preparatorias a nivel local, ${ }^{43}$ en las que, por regla general, se ratificaba el Pacto Militar-Campesino, se proclamaba "líder campesino" a Bánzer y se suscribían documentos diversos entre representantes del gobierno y de los campesinos.

Así, salvo algunas federaciones departamentales y centrales locales, el gobierno controló la CNTCB y, al llevarse a cabo, el 9 de enero de 1972, el "VI" Congreso Nacional Campesino en Sacaba, se reactualizó el Pacto y se nombró a Bánzer líder nacional. ${ }^{44}$

La injerencia estatal en las organizaciones campesinas no estuvo exenta de resistencia y violencia, sobre todo en los periodos electorales del sector. En cuanto a la persecución y represión de campesinos opositores, se sabe que se inició tempranamente: desde finales de 1971, comunidades del altiplano (Achacachi, sobre todo) fueron asediadas por el ejército, igual que algunos lugares cercanos a las minas del norte de Potosí; varios líderes colonizadores fueron asesinados en Santa Cruz y lo mismo ocurrió con dirigentes de Cliza y Ucureña en Cochabamba. ${ }^{45}$

Al iniciarse 1974 , en un ambiente de debilitamiento de los órganos polí. ticos y ascenso de las demandas de apertura política de la sociedad, el régimen de Bánzer enfrentó un problema en la esfera económica: debido al bajo precio que recibían por algunos

43 Ver algunas de la reuniones y concentraciones mencionadas por Flores, "Estado", 1986, pp. $468-470$.

${ }_{44}$ Ibid., pp. 465.469 y 496.499.

45 Iriarte, Sindicalismo, 1980 , pp. 59 y 60. artículos básicos, los productores los contrabandeaban a paises limítrofes donde obtenían mejores precios, provocando desabasto y carestía. Con el fin de paliar este problema y argumen. tando que los precios al consumidor de tales productos se habían mantenido artificialmente, el régimen emitió la Resolución Ministerial núm. 15600, a través de la cual se dieron a conocer los nuevos precios a los compradores de los artículos en cuestión; también se emitió el Decreto Supremo núm. $11300^{46}$ que determinaba la creación de un bono mensual de ayuda para los trabajadores activos y pasivos de las empresas.

Estas medidas, apoyadas por algunas fracciones de las Fuerzas Armadas y por algunos grupos de derecha, en general causaron gran descontento, tanto en los sectores populares como en los empresariales. ${ }^{47}$ Dado que el campesino resultaba doblemente afectado, por su condición más vulnerable como consumidor y por no contar ni siquiera con la compensación de los bonos, ${ }^{48}$ las manifestaciones de protesta y resistencia cobraron fuerza a nivel nacional.

En Tolata y Epizana, pertenecientes a los valles de Cochabamba, donde el sindicalismo y el pacto tenían más influencia, se originó una de las movilizaciones campesinas más importantes contra el régimen de Bánzer, con la

46 Sobre estos decretos consúltese: Flores, "Estado", 1986, pp. 480-486.

${ }^{47}$ Acerca de las movilizaciones véase ibid., pp. $486-492$.

48 Ver el estudio "Tendencia al deterioro de la economía campesina" y "Marco socio-político" en ibid., pp. 378-483. 
consiguiente represión. ${ }^{49}$ No obstan. te, poco a poco la protesta se extendió por todo el país. En los valles y yungas norpotosinas las comunidades organizaron su defensa y reivindicación frente a las políticas estatales, defensa en la que se daba un fuerte contenido de afirmación étnica. Entre tanto, en La Paz, la oficial ista CNTCB, declaró públicamente su apoyo a las medidas y al mandatario. 50

Por esa época, ex líderes barrientistas formaron en Cochabamba una Confederación Clandestina paralela a la CNTCB. ${ }^{51}$ Asimismo, dirigentes pazestenssoristas y la Democracia Cristiana organizaron en los valles un Comité de Bases del Campesinado Boliviano ( $C B C B$ ). Desde sus inicios estas agrupaciones desconocieron a los dirigentes oficialistas, al Pacto MilitarCampesino y al propio gobierno.

Como se anotó antes, en el altiplano, donde se combinaron la organización de la comunidad con una dinámica sin. dical, desde finales de los sesenta, un grupo de jóvenes aimaras -enarbolando la figura de Tupac Katari- venían ganando espacios en los sindicatos campesinos, sobre todo en el departamento de La Paz. En 1972 se reorganizó un centro cultural que reunió a los kataritas decididos a luchar, entre otras cosas, por la independencia del sindicalismo campesino; al año siguiente dieron a conocer sus premisas

49 CERFS, Movimiento, 1981 , pp. 20 y 21 ; Iavaud, "Los campesinos", 1986, p. 295; Flores, "Estado", 1986, pp. 490 y 491; Rivera, "Apuntes", 1985, p. 199; Iriarte, Sindicalismo, 1980, p. 95 .

50 Flores, "Estado", 1986, p. 489.

51 Iriarte, Sindicalismo, 1980, p. 61. ideológicas y su programa de reivindicaciones campesinas a través de un im. portante documento conocido como "Manifiesto de Tiahuanacu". ${ }^{52} \mathrm{El}$ movimiento logró fortalecerse poco a poco extendiéndose por algunos sindicatos de base, subcentrales y centrales altiplánicas.

A partir de la masacre de Tolata, el movimiento katarista declaró su oposición.abierta al Pacto Militar-Campesino; ${ }^{53}$ con ello se acentuó la presión del Estado sobre el katarismo: persiguiendo a sus dirigentes, anulando la personalidad jurídica del centro cultural, confiscándole bienes, etc. Por tanto, las direcciones eran obligadas a trabajar clandestina o semiclandestinamente, lo que noles impidió ganar espacios dentro del aparato sindical oficialista que, para ese momento, se hallaba en franca descomposición. De esta manera, dentro de la clandestinidad, se formó la Confederación Nacional de Trabajadores Campesinos Tupac Katari (CNTCB/TK),${ }^{54}$ contando con apoyo en La Paz, Oruro y Chiquisaca.

Ante una creciente inestabilidad política, en noviembre de 1974 se produjo un significativo cambio institucional: el gobierno encabezado por el coronel Bánzer y secundado por las Fuerzas Armadas anunció, a través de los Decretos Presidencial 11946 y Ley $11947^{55}$ la implantación de lo que denominaron "Nuevo Orden", esto es, la

52 Vid., "Manifiesto de Tiahuanacu" en Rivera, Oprimidos, 1986, Anexo 4, pp. 177-185.

${ }_{53}^{3}$ Rivera, “Apuntes", 1985, p. 203.

${ }^{54}$ Iriarte, Sindicalismo, 1980, p. 61.

55 Ver fragmentos del contenido y algunos comentarios de estos dos decretos en Quiroga, Bolivia, s.f., pp. 28.35. 
permanencia de los militares en el poder hasta 1980 excluyendo a los partidos políticos, aplicando una política estatal inspirada en doctrinas de Seguridad Nacional y de desarrollismo tecnocrático e imponiendo la Ley de Servicio Civil Obligatorio.

A partir de tales decretos, que prohibían las organizaciones sindicales independientes e imponían los llamados "coordinadores", en todos los sectores laborales se generalizó el descontento y las manifestaciones de repudio. Por su parte, los campesinos de las agrupaciones oficialistas lo aceptaron con relativa rapidez; sin embargo, ante la protesta de algunos dirigentes que eran afectados en sus intereses particulares, se elaboró y aprobó al año siguiente un nuevo estatuto campesino en el que se mantuvieron algunos elementos de la organización anterior a la que no le atribuyeron el nombre de sindicato, sino de "núcleo". La CNTCB mantuvo su relación con Bánzer a través del Pacto MilitarCampesino.

Paradójicamente, la persecución y el incremento de la represión contra cualquier manifestación popular incluyendo, desde luego la de los campesinos, provocó que se fortalecieran de manera semiclandestina o clandestina las pocas organizaciones independientes que se habían desarrollado antes y que surgieran otras también interesadas en la autonomía.

Para finales de 1977, delegados campesinos de distintos puntos del país, reunidos en Ayo Ayo (La Paz) para conmemorar el aniversario de la muerte de Tupac Katari, decidieron organizar la oposición del Pacto Militar-Campesino. Por tal motivo la CNTCB/TK "salió de la clandestinidad y se convirtió en el desafío cada vez más poderoso y representativo, frente a la organización oficialista manejada y carente de bases". ${ }^{56}$ Desarrollaron paralelamente una intensa campaña de reorganización en centrales y subcentrales y celebraron, en marzo de 1978, el "VII" Congreso Nacional. ${ }^{57} \mathrm{~A}$ partir de la CNTCB/TK, surgieron dos agrupaciones más bien políticas: el Movimiento Indio Tupac Katari (MIT$\mathrm{KA}$ ), con una marcada línea indigenista y autonomista, y el Movimiento Revolucionario Tupac Katari (MRTK), proclive al establecimiento de alianzas con organismos obreros y de izquierda. ${ }^{58}$

Al mismo tiempo se reorganizó y afilió a la $\mathrm{COB}$-recientemente fortalecida-la Confederación de Colonizadores (CC). Adherida también al máximo orga. nismo de los trabajadores, se formó la Confederación Independiente de Campesinos de Bolivia (CICB), en la que se integraron UCAPO y BCI. De ella se desprendería posteriormente la Confederación Nacional de Trabajadores Campesinos de Bolivia Julián Apaza (CNTCB/JA), así como dos agrupaciones más que conservaron el nombre de la matriz CICB: una ligada a los cobistas y otra más cercana al oficialismo. ${ }^{59}$

\section{VIRTUAL RUPTURA DEL PACTO Y FORTALECIMIENTO DE LA AUTONOMIA}

La gran cantidad de conf lictos sociales y políticos suscitados durante los gobiernos militares, trajo como conse-

\footnotetext{
56 Iriarte, Sindicalismo, 1980, p. 61.

57 Cárdenas, "Notas", 1985, p. 97.

58 Iriarte, Sindicalismo, 1980, p. 65.

59 Ibid., p. 130.
} 
cuencia el paulatino desprestigio de las Fuerzas Armadas; de alli que el propio Bánzer y una fracción de ellas se propusieran llevar a cabo un retiro "ordenado y honroso" de la institución para dar paso a un proceso de democracia viable y controlada. ${ }^{60}$

En julio de 1978 se llevaron a cabo los comicios pero fueron anulados debido a las denuncias de fraude; ante esto, el candidato oficialista, general Juan Pereda -autonombrándose triunfador-obligó a Bánzer a dejarle el gobierno. El ascenso de Pereda al poder, por la vía golpista, abrió un nuevo periodo de inestabilidad política en el que, si bien se realizaron otros dos procesos electorales (1979 y 1980), el gobierno fue usurpado por varios generales y ocupado por dos civiles. Finalmente, en un contexto de agudización de las luchas populares cuyo punto de convergencia era el retorno al orden constitucional, los militares dejaron el gobierno en manos de los civiles de la Unión Nacionalista del Pueblo (UDP), encabezados por Hernán Siles Zuazo, en octubre de 1982.

La apertura política y la realización de comicios en 1978, 79 y 80 , en la que los trabajadores del campo han tenido un papel protagónico, si bien ha favorecido el fortalecimiento de las organizaciones campesinas, también ha producido su multiplicación y diversificación (ideológica y política) como resultado de la recomposición de las fuerzas sociales y políticas generadas en ese ambiente.

En 1978 había alrededor de seis

60 Ardaya, "Ejército". 1985, p. 44. agrupaciones campesinas que, ligadas o no a algún partido o frente, participaban en las elecciones. Por un lado, ligadas directamente con alguna organización política, se hallaban: la oficialista CNTCB que, manteniendo vigente el Pacto Militar-Campesino y a sus coordinadores, apoyaba a Pereda; el CBCB que respaldó primero al general René Bernal y del que al poco tiempo se separó, para seguir al MNR; el llamado Comité de Bases del Campesinado Revolucionario (CBCR); la CICB ligada al PC-ML y al Frente de Izquierda Revolucionaria (FRI) de reciente creación; y el MRTK aliado a UDP. Por otra parte, como relativamente independientes estaban: el MITKA, con sus propios candidatos; así como la CNTCB/TK y la CC, cuyos integrantes apoyaban al candidato de su preferencia a título personal, pero sin comprometer al organismo como tal. ${ }^{61}$

Ante el fraccionamiento del movimiento campesino, durante el gobierno de Padilla (1978-79), la búsqueda de representatividad ante las bases y la independencia y unificación de las organizaciones sindicales campesinas pasaron a un primer plano. ${ }^{62}$

Con el fin explícito de revisar el Pac. to Militar-Campesino y de restringir la influencia del Estado en el campo, el gobierno creó un Comité Unificado de Campesinos que logró conjuntar prác. ticamente a todas las organizaciones campesinas -excepto a la $\mathrm{CC}-$ por un breve lapso, hasta que las divergencias respecto al Pacto y a la adhesión cam. pesina a la COB se hicieron insalvables.

${ }^{61}$ Iriarte, Sindicalismo, 1980, p. 65.

62 Ibid., p. 67. 
Entre tanto, la $\mathrm{COB}$ también alentó la unificación sindical campesina y fue seguida por las CC, CNTCB/TK, CICB (Huaynapaco) y CNTCB/JA. ${ }^{63}$

El Comité Unificado celebró un Congreso, en Sucre, en mayo de 1979, al que asistieron las CBCR, CBCB y uno de los sectores de CICB y donde se pronunciaron contra el Pacto Militar-Campesino y en pro de la integración con la COB. Paralelamente, en La Paz, los sectores de Pascual Gamón de la CNTCB y de Alarcón de la CNCB realizaron su propio Congreso y se declararon en favor de mantener vigente el pacto.

En junio siguiente, se verificó en La Paz el Congreso de Unificación alentado por la $\mathrm{COB}$, en el que se fundó la Confederación Sindical Única de los Trabajadores Campesinos de Bolivia (CSUTCB), con la integración de las CNTCB/TK, CNTCB/JA, y parte de CICB. En el Congreso se

reafirmó la independencia de clase del sindicalismo campesino frente a gobiernos y partidos políticos, [se] descono. ció el Pacto Militar-Campesino, [se] rechazó a los ex coordinadores y todo tutelaje [a] que [se] pretende someter al campesinado, y [se] reafirmó la unidad del campesinado con obreros y pucblo explotado. 64

La CSUTCB, pese a no contar con el reconocimiento del gobierno, extendió su inf luencia por diversas regiones.

No obstante los intentos de unificación, en las elecciones generales de 1979 las organizaciones campesinas en

${ }^{63}$ Flores, "Estado", 1986, pp. 498.503; Iriarte, Sindicalismo, 1980, pp. 68 y 69.

${ }^{64}$ Iriarte, Sindicalismo, 1980, p. 70. recomposición mostraron una amplia gama de posiciones políticas respecto a los candidatos presidenciales. ${ }^{65}$

Pasados estos comicios, las organizaciones campesinas volvieron a orientarse hacia la unificación formán. dose dos grupos cada vez más diferenciados: uno proclive al oficialismo y el otro volcado a la autonomía, a la defensa de los intereses de las bases. Este segundo grupo, constituido por CSUTCB y CC, tuvo una significativa participación contra el golpe de Alberto Natusch (en noviembre de 1979) ya que, luchando al lado de los cobistas y del pueblo en general, lo obligaron a retirarse; otro tanto hicieron contra las medidas económicas instrumentadas por el gobierno de Lidia Gueiler (entre finales de 1979 y principios de 1980), esta vez incluso sin la intervención de la $\mathrm{COB} .{ }^{66}$ Por todo lo anterior, estas dos agrupaciones lograron el reconocimiento de sus bases como organizaciones únicas y representativas, independientes de gobierno y parti$\operatorname{dos}^{67} \mathrm{y}$ fueron ellas las que dirigieron las luchas reivindicativas de los campesinos durante la década de los ochenta.

\section{AIGUNAS CONSIDERACIONES FINAI.ES}

Las organizaciones campesinas se desenvolvieron en el periodo estudiado - como se ha visto arriba- entre la oficialidad y la autonomía por diversos motivos. Por una parte, las características económico-sociales, étnicas y

\footnotetext{
65 Ibid., p. 67.

${ }^{66}$ Flores, "Estado", 1986, pp. 504.516.

${ }^{67}$ Iriarte, Sindicalismo, 1980, p. 7.
} 
culturales, así como la tradición combativa de los campesinos acordes con las diferencias regionales, repercutieron en el interior de las agrupaciones agrarias y en los vínculos de éstas con otros sectores. Por otra parte, de acuerdo con el proyecto de cada uno de los gobernantes civiles y, sobre todo, militares - condicionados, en buena medida, por los intereses de la clase dominante interna y de los grupos extranjeros-, las relaciones de los campesinos entre sí y con los gobernantes adquirieron diversos grados de importancia que influyeron en las formas organizativas de la población rural. Finalmente, cabe subrayar que -no obstante las fluctuaciones y, de alguna manera, por ellas- la presencia y activismo de las organizaciones campesinas ha sido y es de primer orden en la sociedad boliviana contem. poránea.

\section{BIBILIOGRAFÍA}

-Albó, Xavier y Josep M. Barnadas, La cara campesina de nuestra historia, UNITAS, La Paz, 1985.

-Antezana, Luis, Historia secreta del MNR. La revolución de 1952, Juventud, La Paz, 1988, vol. 7 .

-Ardaya, Gloria, "Democracia en Bolivia" en Bolivia, democracia y participación 1952-1982, Fr.ACSO/Bolivia, La Paz, 1985.

-Ardaya, Gloria, "Ejército, ¿crisis para la transición?" en Estado y sociedad, FLAC. So/Bolivia, La Paz, año 1, núm. 1, invierno de 1985.

-Canelas, Amado, Mito y realidad de la Reforma Agraria, Los amigos del libro, La Paz, 1966.

-Cárdenas, Víctor Hugo, "Notas sobre la recuperación y la construcción de la democracia sindical campesina" en Bolivia: democracia y participación 1952-1982, Fl.ACSO/Bolivia, La Paz, 1985.

-Castillo A., Walter del, Compilación legal de la Reforma Agraria, Fénix, La Paz, 1955.

-CERES, Movimiento campesino y etnicidad (Documento base del subdebate andino y subproyecto del caso boliviano), $\mathrm{CE}$ RES/UNRISD, La Paz, 1981

-Dandler, Jorge, "Campesinos y reforma agraria en Cochabamba (1952-1953): dinámica de un movimiento campesino en Bolivia" en Bolivia: las fuerzas históricas del campesinado, UNRISD-CERES, Suiza, 1986.

-Dandler, Jorge, "La Ch'ampa guerra de Cochabamba: un proceso de disgregación política" en Bolivia: las fuerzas históricas del campesinado, UNRISD/CERES, Sui$\mathrm{za}, 1986$.

-Fernández, Wilson, El gran culpable (La responsabilidad de los EE. UU. en el proceso militar uruguayo), Atenea, s.1., 1986.

-Flores, Gonzalo, "Estado, políticas agrarias y luchas campesinas: revisión de una década en Bolivia" en Bolivia: las fuerzas históricas del campesinado, UNRISD/ CERES, Suiza, 1986.

-Huizer, Guerrit, El potencial revolucionario del campesinado en América Latina, Siglo XXI Editores, México, 1973.

-Insulza, José Miguel, "La primera Guerra Fría: percepciones estratégicas de la amenaza soviética (1945-1963)" en Estados Unidos. Una visión latinoamericana, Fondo de Cultura Económica, México, 1984 (Lecturas núm. 53).

-Iriarte, Gregorio, Sindicalismo campesino:ayer, hoyy mañana, CIPCA, La Paz, 1980.

-Jiménez, Maritza, "El Estado boliviano $\mathrm{y}$ las luchas campesinas del altiplano y los valles (1952-1968)", FLACSO/éxico, México, 1980 (tesis de maestría).

-Lavaud, Jean Pierre, "Los campesinos frente al Estado" en Bolivia: las fuerzas 
historicas del campesinado, UNRISD/CERES, Suiza, 1986.

- Lazarte, Jorge, Movimiento obrero y proceso político en Bolivia (Historia de la COB (1952-1987), ILDIS, La Paz, 1989.

-Llosa, José Antonio, René Barrientos Ortuña, paladín de la bolivianidad, Novedades, La Paz, 1966.

-Menjívar, Rafael, "La Reforma Agraria en Bolivia" en Reforma Agraria en América Latina, Universitaria, San Salvador, 1969.

-Miranda, Mario, "Bolivia" en Radicalización y golpes de Estado en América Latina, FCPYS.UNA M, México, 1973.

-Miranda, Mario, "El populismo en Bolivia" en El populismo en América Latina, UNAM/CCYDEL, México, 1983 (Nuestra América, núm. 7).

-Prado, Gary, Poder y Fuerzas Armadas 1949-1982, Los amigos del libro, La Paz, 1984.

-Quiroga S. C., Marcelo, Bolivia recupera la palabra: Juicio a la dictadura 1979, MEP, La Paz, s.f.

-Rivera, Silvia, "Apuntes para una historia de las luchas campesinas en Bolivia
(1900-1978)" en Historia política de los campesinos en América Latina, ISS.UNAM, México, 1985, t. 3.

"Luchas campesinas contemporáneas en Bolivia: el movimiento 'katarista': 1970-1980" en Bolivia, hoy, Siglo XXI Editores, México, 1983.

- Oprimidos pero no vencidos; luchas del campesinado aimara y quechua en Bolivia 1900-1980, ONU, Ginebra, 1986.

-Urioste, Miguel, El Estado anticampesino, El Buitre, Cochabamba, 1984.

-Urquidi, Arturo, Bolivia y su Reforma Agraria, Universidad, La Paz, 1969.

, El feudalismo en América Latina y la Reforma Agraria en Bolivia, Universidad, Cochabamba, 1966.

-Zavaleta, René, "Consideraciones generales sobre la historia de Bolivia (1932. 1971)" en América Latina: historia de medio siglo, IIS-UNAM/Siglo XXI Editores, México, 1982, vol. 2.

-Zavaleta, René, Lo nacional-popular en Bolivia, Siglo XXI Editores, México, 1984. 


\section{SECUENCIA}

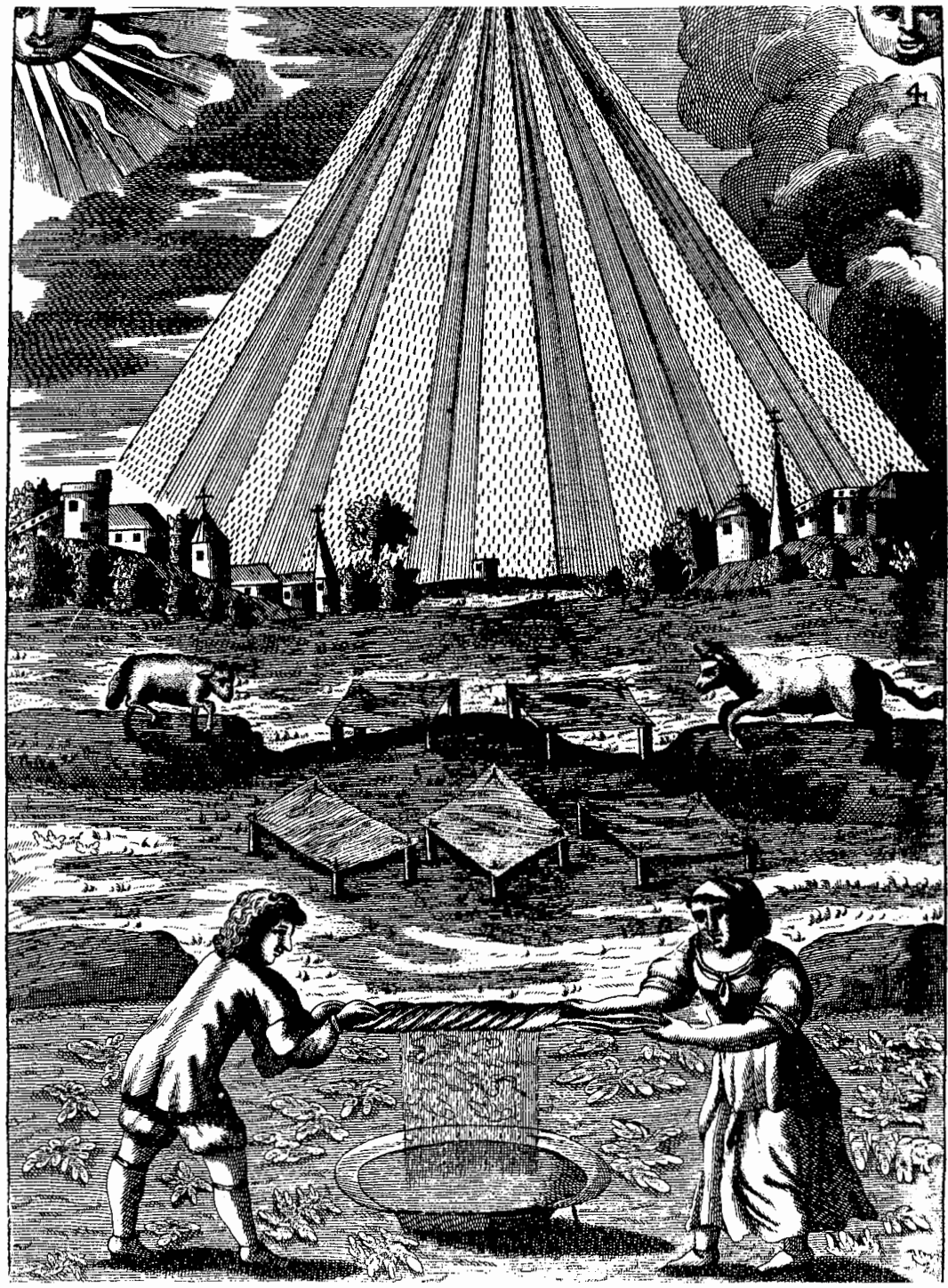

